\title{
Hypertrofic scar - associated ultrasound aspects after thyroidectomy
}

\author{
Florica SANDRU ${ }^{1,2}$, Ana VALEA ${ }^{3,4}$, Simona Elena ALBU ${ }^{1,5}$, \\ Mihai Cristian DUMITRASCU ${ }^{1,5}$, Mara CARSOTE ${ }^{1,6}$ \\ 1"Carol Davila" University of Medicine and Pharmacy, Bucharest, Romania \\ ${ }^{2}$ Elias Emergency University Hospital, Bucharest, Romania \\ ${ }^{3}$ Clinical County Hospital, Cluj-Napoca, Romania \\ 4"Iuliu Hatieganu" University of Medicine and Pharmacy, Cluj-Napoca, Romania \\ ${ }^{5}$ Emergency University Hospital, Bucharest, Romania \\ 6"C.I. Parhon" National Institute of Endocrinology, Bucharest, Romania
}

\section{ABSTRACT}

Scar is part of wound healing and hypertrophic aspects as well as keloids are pathological formation of a scar. Their appearance is seen post-operatory, post-trauma and the consequences are more than cosmetic depending on location, for instance at joins functional impotence is associated. A scar formation involves activation of matrix enzymes, matrix response, local inflammation and fibroblast intervention as well as local cytokines and growth factors action. Our purpose is to introduce to cases of females who developed hypertrophic scars after thyroidectomy in addition to local swelling as revealed by neck ultrasound. The paper is two cases series report. The hormonal assays and ultrasound aspects are provided. A 30-year female with Basedow disease had one month after thyroidectmy TRAb of 2.4 U/l while TSH was 1 of under daily $100 \mu \mathrm{g}$ of levothyroxine. The subject presented a post-operatory hypertrophic scar in addition to the following ultrasound aspect: right area with an inhomogeneous structure of $1 / 1.2 / 4 \mathrm{~cm}$, left area of $1.4 / 1.7 / 4 \mathrm{~cm}$, with multiple images with posterior echo and intense local edema. This is a 44-year female referred for total thyroidectomy (for large goiter). The subject did not develop any peri-operatory complication. The histological report showed chronic autoimmune thyoiditis background of focal type in addition to nodules of colloidal and cystic adenomatosis with hyperplasic epithelium. One month later TSH was normal under levothyroxine. The subject presented a post-operatory hypertrophic scar in addition to ultrasound aspect of edema in association with inflammatory lymph nodes at lateral cervical level of $0.6 / 0.2 \mathrm{~cm}$ maximum diameter. It is still a matter of debate to classify the high risk patients for developing post-thyroidectomy scars.
\end{abstract}

Keywords: hypertrophic scar, keloids, thyroidectomy

Abbreviations: FreeT4 = thyroxine, TSH = thyroid stimulating hormone,

$\mathrm{TRAb}=\mathrm{TSH}$ receptor antibody

\section{INTRODUCTION}

Scar is part of wound healing and hypertrophic aspects as well as keloids are pathological formation of a scar (1). Their appearance is seen post-operatory, post-trauma and the consequences are more than cosmetic depending on location, for instance at joins functional impotence is associated (1). Hypertrophic scars are distinct from keloids which are more severe (1). Hypertrophic aspects are more frequent after burns or skin trauma (1). A scar formation involves activation of matrix en- 
zymes, matrix response, local inflammation and fibroblast intervention as well as local cytokines and growth factors action (1). Scar itself is a negative consequence of a skin aggression due to high temperature, trauma, cuts, regardless that may be iatrogenic (related to a surgical act) (2). Hypertrophic pattern is due to fibroblasts/myofibroblasts contraction and increased matrix deposits and collagen formation (2). This type of skin response is actually a fibro-proliferative condition of the derma (3). A part from inflammation mediators and local growth factors, recently peptide have been proven to play an active role even a therapeutic one as activator of normal fibroblast response (3). Local fibrosis causing aesthetic and functional damage increases the economic burden (4). Anarchic activation of matrix metalloproteinases is a contributor to hypertrophic scar, too (5).

\section{AIM}

Our purpose is to introduce to cases of females who developed hypertrophic scars after thyroidectomy in addition to local swelling as revealed by neck ultrasound.

\section{METHOD}

The paper is two cases series report. The hormonal assays and ultrasound aspects are provided.

\section{CASE DATA}

\section{Case 1}

This is a 30 - year old non-smoking female coming from non-endemic area. The family medical history is negative. She has Basedow - Graves' disease since last 7 years and she has been treated with anti-thyroid drug (thiamazol of different doses). On admission, the clinical evaluation is suggestive for hyperthyroidism and a large, mobile goiter is detected. TSH (thyroid stimulating hormone) is $0.05 \mu \mathrm{Ul} / \mathrm{ml}$ (normal values between 0.5 and $4.5 \mu \mathrm{Ul} / \mathrm{ml}$ ) and FreeT4 (thyroxine) is 19.5 pmol/I (normal limits between 17 and $19 \mathrm{pmol} / \mathrm{I}$ ) under daily $5 \mathrm{mg}$ of thiamazol. The thyroid autoimmunity shows a TRAb (TSH receptor antibody) of $18 \mathrm{U} / \mathrm{I}$ (normal levels < $1 \mathrm{U} / \mathrm{I}$ ). The eye examination showed right/left eye proptosis of 16/15.5 $\mathrm{mm}$ (millimeter). Thyroid ultrasound reveals: right lobe of 3.9/2.8/6.5 cm, a left lobe of $3.1 / 2.9 / 6 \mathrm{~cm}$ (centimeter). Right lobe has a $3 \mathrm{~cm}$ hypoechoic nodule (Figure 1). After normalization of thyroid function due to increased dose of thiamazol, the patient was referred for total thyroidectomy. No complications were developed around the surgical act. Histological report confirmed classical
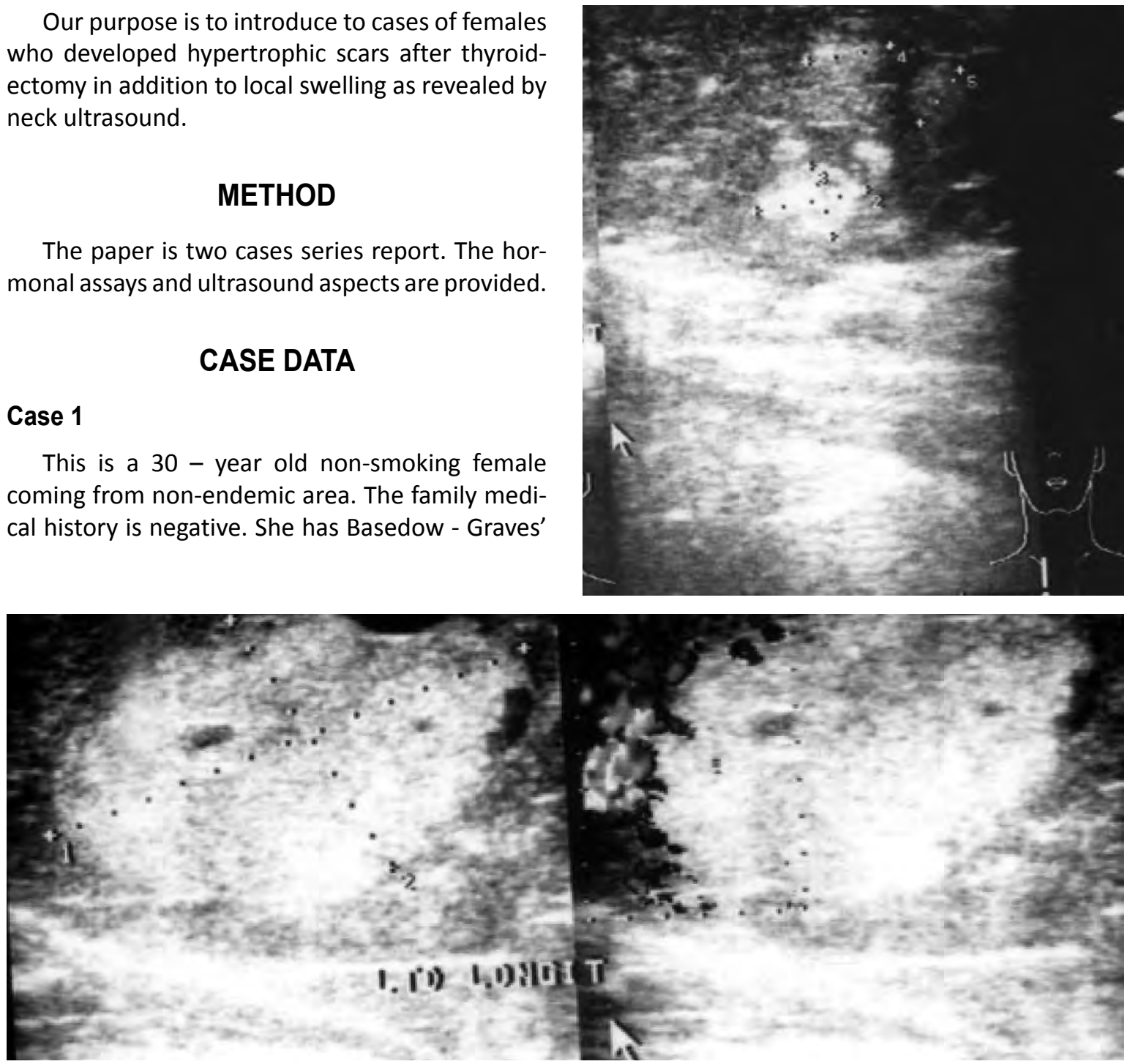

FIGURE 1. Thyroid ultrasound on a 30-year old patient with Basedow disease. Right lobe of 3.9/2.8/6.5 cm and a $3 \mathrm{~cm}$ hypoechoic nodule 
Basedow disease. One month later, TRAb was still high, of $2.4 \mathrm{U} / \mathrm{I}$ while TSH was 1 of under daily $100 \mu \mathrm{g}$ of levothyroxine. The subject presented a post-operatory hypertrophic scar in addition to the following ultrasound aspect: right area with an inhomogeneous structure of $1 / 1.2 / 4 \mathrm{~cm}$, left area of $1.4 / 1.7 / 4 \mathrm{~cm}$, with multiple images with posterior echo and intense local edema (Figure 2). She will be followed both for dermatological aspects and endocrine substitution.

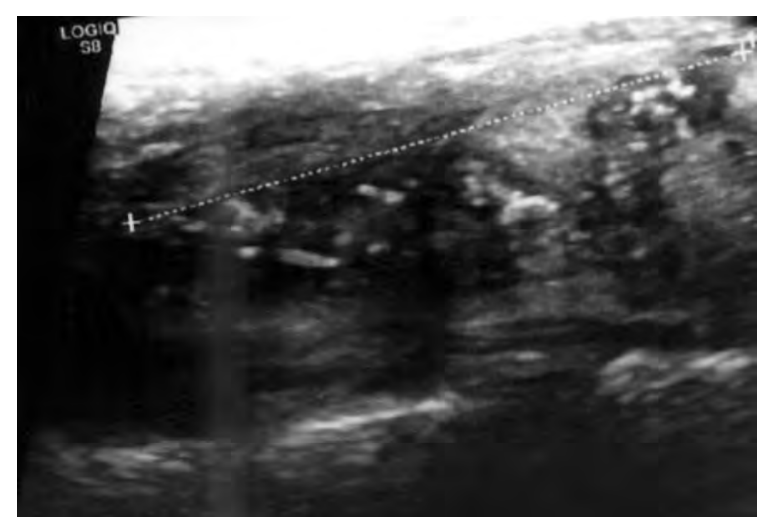

Right lobe - longitudinal aspect

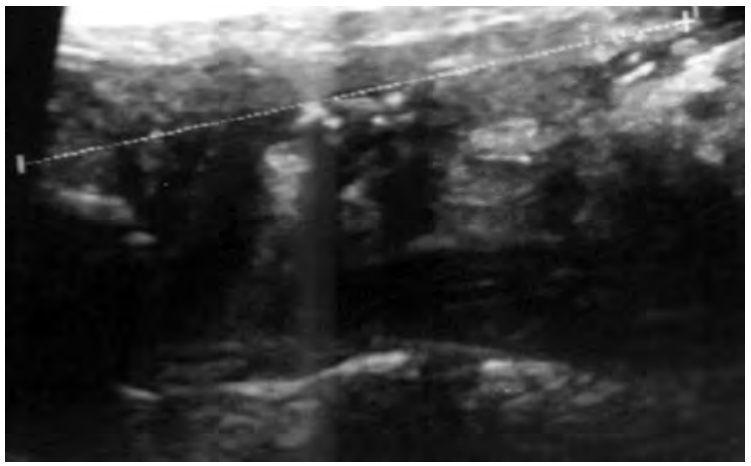

Left lobe - longitudinal aspect

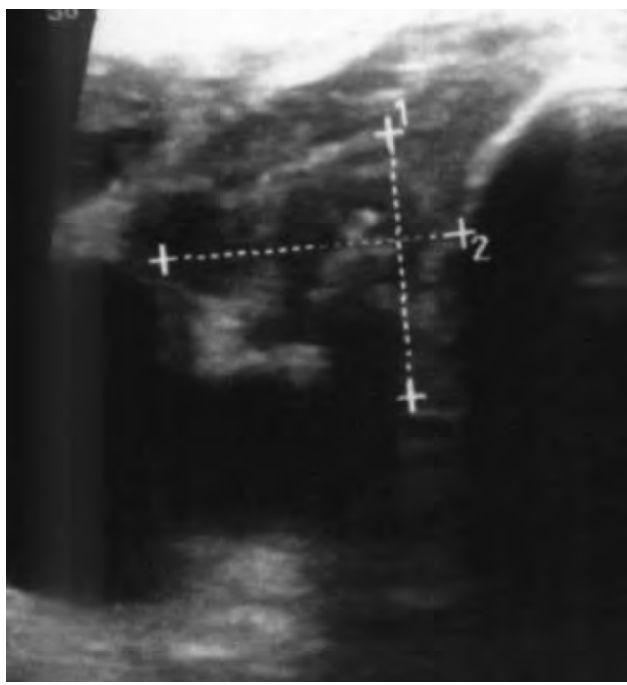

Left lobe - transversal aspect

FIGURE 2. Post-thyroidectomy neck ultrasound aspect (one month after the procedure)

\section{Case 2}

This is a 44-year old non-smoking female coming from endemic area. The family medical history is negative. She has multinodular goiter with negative autoimmunity. On admission, the clinical evaluation is normal except for symmetrical goiter. She accuses mild local compressive symptoms. $\mathrm{TSH}$ is $1 \mu \mathrm{Ul} / \mathrm{ml}$ (normal values between 0.5 and $4.5 \mu \mathrm{Ul} / \mathrm{ml}$ ). Thyroid ultrasound reveals: right lobe of $1.9 / 2.1 / 4.3 \mathrm{~cm}$, a left lobe of $2 / 2 / 6 \mathrm{~cm}$. Right lobe has a taller than wide nodule of $0.6 / 1 / 0.7 \mathrm{~cm}$, and an inferior conglomerate of $3.2 / 2.6 / 2 \mathrm{~cm}$. The patient was referred for total thyroidectomy. The subject did not develop any peri-operatory complication. The histological report showed chronic autoimmune thyoiditis background of focal type in addition to nodules of colloidal and cystic adenomatosis with hyperplasic epithelium. One month later TSH was $1.4 \mu \mathrm{UI} / \mathrm{ml}$ while the subject was treated with $100 \mu \mathrm{g}$ of levothyroxine per day. The subject presented a post-operatory hypertrophic scar in addition to the following ultrasound aspect: right thyroid area of $0.45 / 0.42 \mathrm{~cm}$, left area of $0.44 / 0.52 \mathrm{~cm}$, with hypoechoic structure suggesting an edema in association with inflammatory lymph nodes at lateral cervical level of 0.6/0.2 $\mathrm{cm}$ maximum diameter (Figure 3 ).

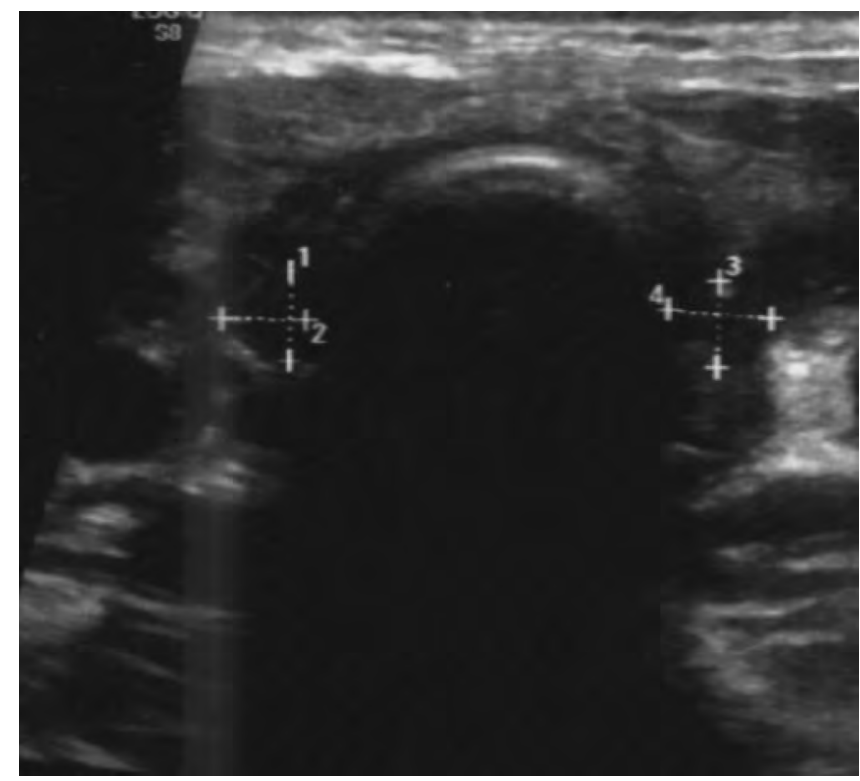

FIGURE 3. A 44-year old female with hypertrophic scar and postoperatory edema. Right thyroid area of $0.45 / 0.42 \mathrm{~cm}$, left area of $0.44 / 0.52 \mathrm{~cm}$, with hypoechoic structure suggesting an edema

\section{DISCUSSION}

We introduce two cases of total thyroidectomy that actually were evaluated one month after surgery and the post-operatory scars seem hyper- 
trophic. The evaluation is still too early to fully predict the partial remission or the transformation to keloids (6). Close follow-up is necessary in order to adequate management. Also, the post-operatory ultrasound aspect is uncommon due to the presence of distortions or edema as mentioned before. Generally the risk is related to factors like race (Caucasians have lower risk than non-Caucasians), collagen conditions (as Ehlers Danlos syndrome) etc. (7). The risk factors have been introduced in specific scores by some working groups (6). The guidelines of diagnosis and treatment vary $(6,8)$. Topical solutions seem the most reasonable approach as therapy (8).

\section{The post-operatory complications}

Thyroidectomy is largely used for benign conditions like multinodular goitre but also malignancies like differentiated thyroid cancer of papillary and follicular type as well as medullar cancer and maybe anaplastic carcinoma depending on case or even thyroid metastases (if any) $(9,10,11)$ (Figure 4 and Figure 5). Hyper-function and even electrolytes anomalies must be treated before surgery due to high cardiovascular risk $(9,10,11,12)$. Post-thyroidectomy complications are described in $0-4 \%$ of cases, an average of $1 \%$ (except for iatrogenic hypothyroidism) $(13,14)$. Among them we mention hypoparathyroidism-related hypocalcemia, edema, neck hematoma, anesthesia and cardiovascular risk during surgery especially if prior cardiac co-morbidities or dys-electrolytemia are presented. A limited number of publications are found related to exclusive risk of keloids and hypertrophic scars after thyroidectomy (15). A case of thyroidectomy via a prior lateral neck scar has been reported (16). A systematic review from 2019 showed that the risk is similar between minimally invasive and video-assisted procedure (17). Robotic remote access surgery at retroauricular level is an alternative to classical incision approach to avoid the visible scars (18). Trans-axillary incision is another alternative to open anterior traditional technique $(19,20)$.

\section{CONCLUSION}

It is still a matter of debate to classify the high risk patients for developing post-thyroidectomy scars.

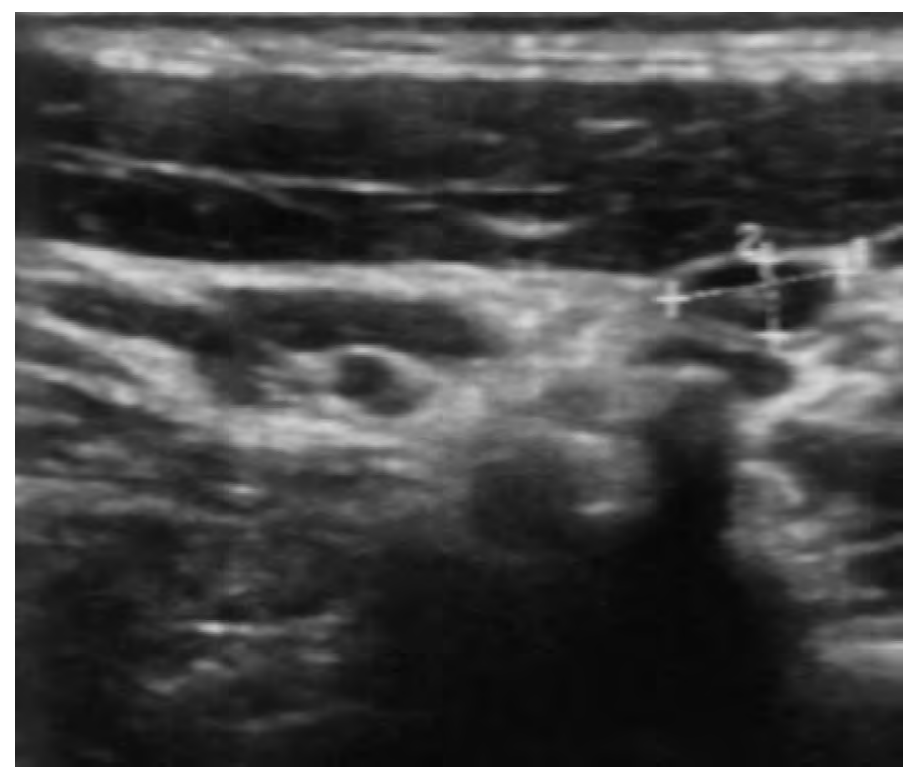

FIGURE 4. Inflammatory lymph nodes at lateral cervical level of $0.6 / 0.2 \mathrm{~cm}$ maximum diameter
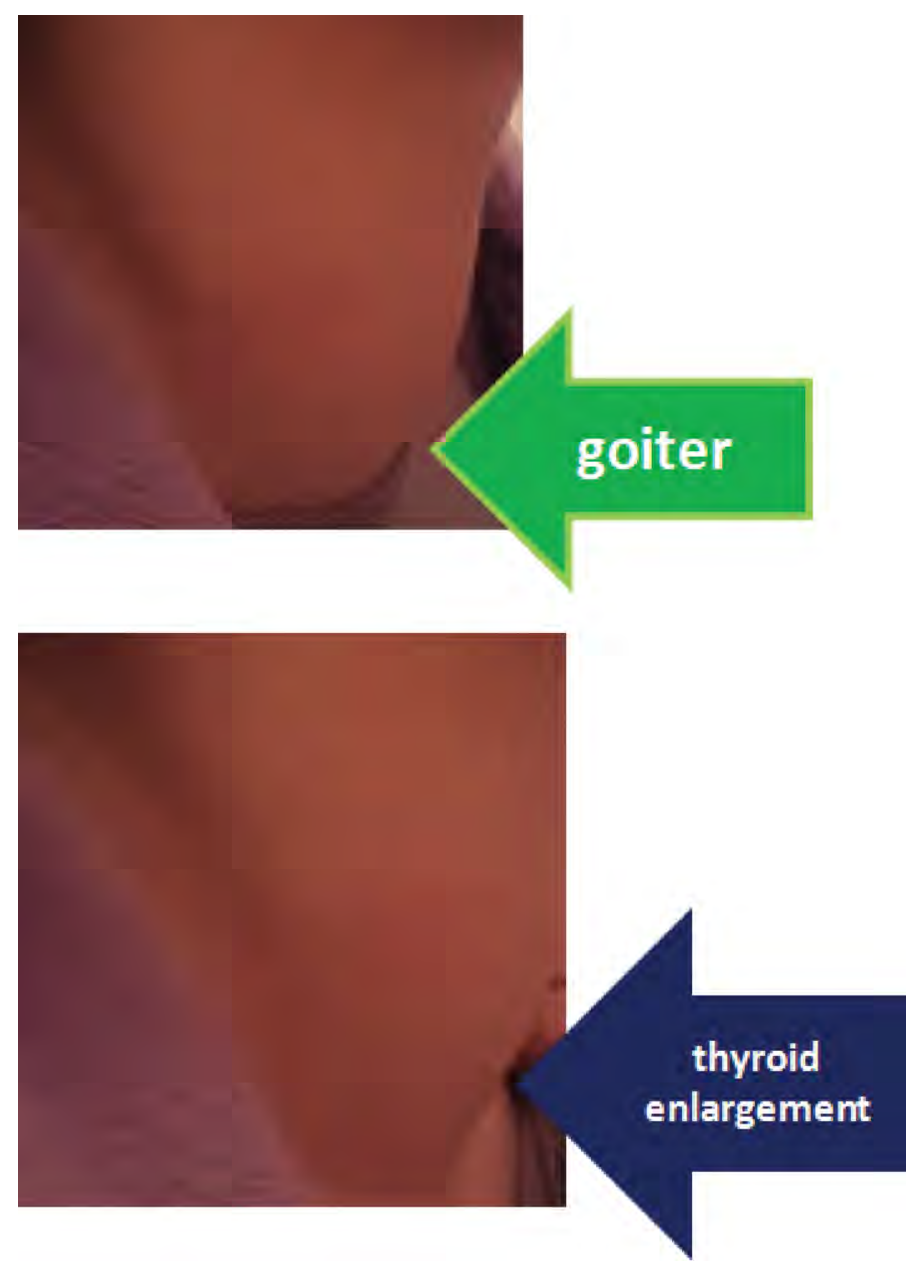

FIGURE 5. Thyroid enlargement of a young female patient with Basedow disease and Graves' eye involvement 


\section{REFERENCES}

1. Rabello FB, Souza CD, Farina Júnior JA. Update on hypertrophic scar treatment. Clinics (Sao Paulo). 2014;69(8):565-73.

2. Lingzhi Z, Meirong L, Xiaobing F. Biological approaches for hypertrophic scars. Int Wound J. 2019 Dec 20.

3. Song J, Li X, Li J. Emerging evidence for the roles of peptide in hypertrophic scar. Life Sci. 2020 Jan 15;241:117174.

4. Padmanabhan J, Maan ZN, Kwon SH, Kosaraju R, Bonham CA, Gurtner GC. In Vivo Models for the Study of Fibrosis. Adv Wound Care (New Rochelle). 2019; 8(12):645-654.

5. Zhang J, Li Y, Bai X, Li Y, Shi J, Hu D. Recent advances in hypertrophic scar. Histol Histopathol. 2018 ;33(1):27-39.

6. Ogawa R, Akita S, Akaishi S, AramakiHattori N, Dohi T, Hayashi T, Kishi K, Kono T, Matsumura $\mathrm{H}$, Muneuchi G, Murao N, Nagao M, Okabe K, Shimizu F, Tosa M, Tosa Y, Yamawaki S, Ansai S, Inazu N, Kamo T, Kazki R, Kuribayashi S. Diagnosis and Treatment of Keloids and Hypertrophic Scars-Japan Scar Workshop Consensus Document 2018. Burns Trauma. 2019 Dec 27;7:39.

7. Ogawa R, Hsu CK. Mechanobiological dysregulation of the epidermis and dermis in skin disorders and in degeneration. J Cell Mol Med. 2013;17(7):817-22.

8. Gold MH, Andriessen A, Bhatia AC, Bitter P Jr, Chilukuri S, Cohen JL, Robb CW13. Topical stabilized hypochlorous acid: The future gold standard for wound care and scar management in dermatologic and plastic surgery procedures. J Cosmet Dermatol. 2020 Jan 6.

9. Carsote M, Albu SE, lorgulescu R, Dumitrascu A, Terzea D, Goldstein A, Poiana C. From vasomotor symptoms to solid and insular papillary thyroid cancer with oxyphil variant areas. Journal of Surgical Sciences. 2015;2(2):87-91.

10. Dumitru N, Ghemigian A, Carsote M, Albu SE, Terzea D, Valea A. Thyroid nodules after initial evaluation by primary health care practitioners: an ultrasound pictorial essay. Archives of the Balkan Medical Union. 2016;51(3):434-438.

11. Poiana C, Carsote M, Ardeleanu C, Terzea D, Avramescu ET, Neamtu MC, Miulescu $\mathrm{RD}$. The value of the immunohistochemistry in a case of gastric neuroendocrine tumor and thyroid metastasis. Rom $\mathrm{J} \mathrm{Morphol}$ Embryol. 2011; 52(1):187-92.

12. Poiana C, Virtej I, Carsote M, Banceanu M, Sajin M, Stanescu B, loachim D, Hortopan D, Coculescu M. Virilising Sertoli-Leydig cell tumour associated with thyroid papillary carcinoma: Case report and general considerations, Gynecol Endocrinol 2010; 26(8):617-622.

13. Paduraru DN, Ion D, Carsote $M$, Andronic O, Bolocan A. Post-thyroidectomy Hypocalcemia - Risk Factors and Management. Chirurgia (Bucur). 2019; 114(5):564-570.

14. Bajwa SJ, Sehgal V. Anesthesia and thyroid surgery: The never ending challenges.
Indian J Endocrinol Metab. 2013; 17(2):228-34.

15. Sahm M, Otto R, Pross M, Mantke R. Minimally invasive video-assisted thyroidectomy: A critical analysis of long-term cosmetic results using a validated tool. Ann R Coll Surg Engl. 2019 Mar; 101(3):180-185.

16. Woo SH. Endoscopic-Assisted Total Thyroidectomy via Lateral Keloid Scar Incision. Clin Exp Otorhinolaryngol. 2014; 7(4):338-41.

17. Scerrino G, Melfa G, Raspanti C, Rotolo G, Salamone G, Licari L, Fontana T, Tutino R, Porrello C, Gulotta G, Cocorullo G. Minimally Invasive Video-Assisted Thyroidectomy: Analysis of Complications From a Systematic Review. Surg Innov. 2019; 26(3):381-387.

18. Alabbas H, Bu Ali D, Kandil E. Robotic retroauricular thyroid surgery. Gland Surg. 2016; 5(6):603-606.

19. Lörincz BB, Möckelmann N, Knecht R. Single-incision transaxillary robotic total thyroidectomy for Graves' disease: Improved feasibility and safety with novel robotic instrumentation. Eur Arch Otorhinolaryngol. 2014;271(12):3349-53.

20. Duncan TD, Rashid Q, Speights F, Ejeh I. Transaxillary endoscopic thyroidectomy: an alternative to traditional open thyroidectomy. J Natl Med Assoc. 2009; 101(8):783-7. 